undergone; and (3) to know the role of SCPSW in psychosocial rehabilitation and social support program including Safe Community initiatives. The end results of the study proposes a strong need for providing Safe living, and a paradigm shift towards SCPSW. The intervention of SCPSW was felt very much because the role of SCPSW during the crises days is immense.

\title{
0002 OCCUPATIONAL ACCIDENTS AND INJURY: COMPREHENSIVE SOCIAL SUPPORT FOR POST-TRAUMA MANAGEMENT OF VICTIMS
}

M M Bagali* Correspondence: CIMR, Santrupti building, 8th cross, H.No.17/2374, Kalyanagar, Dharwad 580 007, Karnataka, India

\subsection{6/ip.2010.029215.2}

The rise and growth of modern industries with much complicated industrial system has given rise to several labour problems in Asia and more so in India. Infact, the sudden impact of industrial revolution leading to rapid industrialisation had a bad effect on Industrial workers, health, safety and safe living. Predominant been the occupational accidents and the resultant injuries. The losses incurred by all sections of labour society are severe and to the large extent, the family members of the effected ones. The after-math psychosocial burden faced and the trauma undergone is sign of caution to all those thinkers who believe in social welfare of the community population. Because, when the accident occurs, the financial compensation is paid easily as per the legislation requirements. The stress, strain and burden undergone leaves the victim in total disarray, and cases probed in the present study revealed suicidal attempts due to lack of social support program and safe community interventions. The enquiry was done at three stages: (1) to know the level of Dysfunction suffered by using apt valid parametric tool; (2) to assess the psycho-social burden 